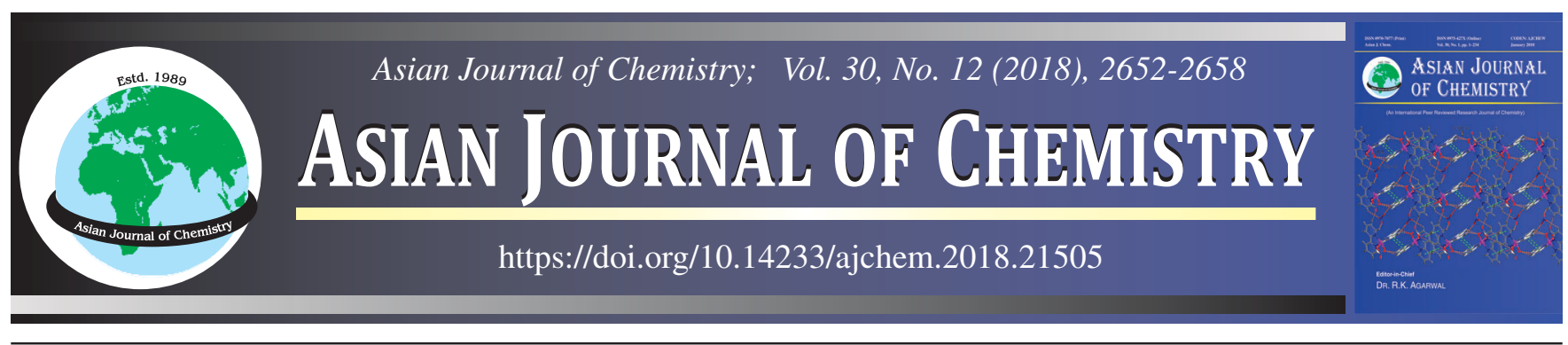

\title{
Influence of Temperature and Concentration of Capping Molecule and bis(N-Cyclohexyl-2-hydroxy-1-naphthaldehydato)manganese(II) as Single Source Precursor for Synthesis of TOPO Capped $\mathrm{Mn}_{3} \mathrm{O}_{4}$ Nanoparticles
}

\author{
T. XABA
}

Department of Chemistry, Vaal University of Technology, P/Bag X021, Vanderbijlpark, South Africa

Corresponding author: Fax: +27 86 6906606; Tel:+27 16 9509820; E-mail: thokozanix@ vut.ac.za

Received: 8 June 2018;

Accepted: 31 August 2018;

Published online: 31 October 2018;

AJC-19127

\begin{abstract}
In this study, the effect of temperature, amount of the precursor and the concentration of the stabilizer on the synthesis of manganese oxide nanoparticles using bis( $N$-cyclohexyl-2-hydroxy-1-naphthaldehydato)manganese(II) complex has been investigated. The precursor was prepared from the chemical reaction of 2-hydroxy-1-naphthaldehyde, amine and manganese salt. The resulting precursor was thermally decomposed into tri- $n$-octylphosphine oxide (TOPO) to synthesize TOPO capped manganese oxide nanoparticles at the temperature ranging from 120 to $200^{\circ} \mathrm{C}$. Various instruments were used to characterize the prepared complex and manganese nanoparticles. The optical band gaps energies of the nanoparticles were decreasing from 1.48 to $1.35 \mathrm{eV}$ when the decomposition temperature was increased.
\end{abstract}

Keywords: Manganese complex, Tri- $n$-octylphosphine oxide, Manganese oxide, Nanoparticles, Semiconductors.

ᄂ - - - - - - - - - - - - - - - - - - - - - - - - - - -

\section{INTRODUCTION}

Metal complexes having nitrogen and phenolic oxygen donor atoms have been of great interest due to their potential application in nanotechnology, medicine and catalysis [1,2]. The metal complexes usually utilized to create prolonged network structures and to coordinate polymers with high structural strength and distinct topologies [3-6]. Transition metal complexes derived from Schiff bases such as salicylaldehyde and other primary amines are one of the most adaptable and most considered systems $[7,8]$. The study based on the synthesis of nanomaterials have gained interest across many different disciplines $[9,10]$. Semiconductor transition metals have studied due to their stimulating properties and applications compared to their bulk materials. Among semiconducting transition metal oxides, manganese oxides have attracted a broad significance. Its structures display oxygen vacancies that supply extra active sites for reduction and oxidation reaction intermediates, particularly those that contain oxygen. These properties are especially significant for catalytic applications such as water oxidation [11-13]. Manganese oxide can subsist in more than five transferable transition states with several structural forms over extensive range of temperatures $[14,15] . \mathrm{Mn}_{3} \mathrm{O}_{4}$ is an important oxide due to its high theoretical lithium-storage capacity and ferromagnetic performance as related to other oxides [16,17]. Manganese oxide nanoparticles have been used in several fields such as electrochemical capacitors [18], immobilization of proteins [19], sensitive biosensors [20], lithiumion batteries [21], removal of dyes [22], biomimetic catalysts [23], etc. Several methods have been used for the synthesis of $\mathrm{Mn}_{3} \mathrm{O}_{4}$ nanoparticles which include chemical bath deposition [24], hydrothermal [25], solvothermal [26], coprecipitation [27], microwave irradiation [28] and surfactant-assisted methods [29]. Among these methods, thermal decomposition technique has been used in the past since it is an innovative method to produce stable monodispersed nanoparticles [30].

Tai et al. [31] reported the preparation and spectroscopic properties of $\mathrm{Mn}$ (II), $\mathrm{Co}$ (II) and $\mathrm{Cu}$ (II) complexes with a novel Schiff base ligand derived from 2,2'-bis(p-methoxylphenylamine) and salicylaldehyde. Ozkaya et al. [32] reported a novel synthetic route to $\mathrm{Mn}_{3} \mathrm{O}_{4}$ nanoparticles and their magnetic evaluation using an oxidation-precipitation method. Their X-ray

This is an open access journal, and articles are distributed under the terms of the Creative Commons Attribution-NonCommercial 4.0 International (CC BY-NC 4.0) License, which allows others to copy and redistribute the material in any medium or format, remix, transform, and build upon the material, as long as appropriate credit is given and the new creations are licensed under the identical terms. 
diffraction (XRD) analysis confirmed the tetragonal haussmanite structure of $\mathrm{Mn}_{3} \mathrm{O}_{4}$ with different crystallite sizes. He and coworkers [33] synthesized polyetheramide templated monodisperse $\mathrm{Mn}_{3} \mathrm{O}_{4}$ nanoparticles with controlled size and study based on their electrochemical properties through solvothermal method. They discovered that the higher concentration of polyetheramide block copolymers in the solution resulted in the formation of the smaller $\mathrm{Mn}_{3} \mathrm{O}_{4}$ particles.

Herein, we report the preparation of bis( $N$-cyclohexyl-2hydroxy-1-naphthaldehydato)manganese (II) complex for the synthesis of tri- $n$-octylphosphine oxide (TOPO) capped $\mathrm{Mn}_{3} \mathrm{O}_{4}$ nanoparticles by thermal decomposition method. The effect of temperature, concentration of the capping agent and concentration of the precursor were studied. To the best of our knowledge, synthesis of $\mathrm{Mn}_{3} \mathrm{O}_{4}$ nanoparticles using this particular complex has not been reported so far. The precursor was analyzed with FTIR, TGA and elemental analysis. The optical properties of the synthesized $\mathrm{Mn}_{3} \mathrm{O}_{4}$ nanoparticles were characterized with UV-visible and photoluminescence whereas the morphologies of the particles where measured with X-ray diffraction and TEM.

\section{EXPERIMENTAL}

2-Hydroxy-1-naphthaldehyde, manganese(II) acetate dihydrate, cyclohexamine and tri- $n$-octylphosphine oxide were purchased from Sigma-Aldrich. Methanol, ethanol, acetone and toluene were reagents purchased from Merck chemicals and used without further purification.

Preparation of bis( $N$-cyclohexyl-2-hydroxy-1-naphthaldehydato)manganese(II) complex: The complex was produced using the reported procedure [34-36]. Briefly, an equimolar of cyclohexamine $(10 \mathrm{mmol})$ was added into 2-hydroxy-1naphthaldehyde $(10 \mathrm{mmol})$ in methanol followed by the addition of manganese(II) acetate dihydrate $(5 \mathrm{mmol})$ in methanol into a $100 \mathrm{~mL}$ two-necked flask. The mixture was refluxed at $50^{\circ} \mathrm{C}$ for $3 \mathrm{~h}$. The dark grey precipitate was filtered, washed three times with ethanol and dried in a desiccator. The product was obtained as a very dark brown solid, m.p. $173^{\circ} \mathrm{C}, \mathrm{CHN}$ analysis: Anal. \% calcd. (found) for $\mathrm{C}_{34} \mathrm{H}_{36} \mathrm{~N}_{2} \mathrm{O}_{2} \mathrm{Mn}$ : C, 72.96 (71.29); H, 6.50 (6.40); N, 5.01 (5.08); O, 5.72 (6.72). FT-IR (KBr, $\left.v_{\max }, \mathrm{cm}^{-1}\right): 1634 v(\mathrm{C}=\mathrm{N}), 1391 \mathrm{v}(\mathrm{C}-\mathrm{O}), 615 \mathrm{v}(\mathrm{Mn}-\mathrm{O}), 469$ $v(\mathrm{Mn}-\mathrm{N})$.

Synthesis of $\mathrm{Mn}_{3} \mathrm{O}_{4}$ nanoparticles: Tri- $n$-octylphosphine oxide $(5 \mathrm{~g})$ was mixed with bis( $N$-cyclohexyl-2-hydroxy-1naphthaldehydato)manganese(II) precursor $(0.5 \mathrm{~g})$ in a two necked flask to synthesize manganese oxide nanoparticles. The mixture was refluxed and heated to 120,160 or $200{ }^{\circ} \mathrm{C}$ under nitrogen environment. The temperature was maintained for $1 \mathrm{~h}$. The mixture was then allowed to cool to a temperature of about $70{ }^{\circ} \mathrm{C}$. An addition of methanol $(30 \mathrm{~mL})$ produced a reddish brown precipitate which was separated by centrifugation. The product was washed three times with methanol and re-dispersed in toluene for characterization. To study the effect of concentration of the complex and capping agent, the procedure was repeated with $10 \mathrm{~g}$ of TOPO and $1 \mathrm{~g}$ of complex instead of $5 \mathrm{~g}$ and $0.5 \mathrm{~g}$ at a constant temperature of $160^{\circ} \mathrm{C}$.

Physical measurements: The FTIR spectrum for complex was collected from a Bruker FT-IR tensor 27 spectrophoto- meter in the range 4000 to $400 \mathrm{~cm}^{-1}$. Elemental analysis of the manganese complexes was performed on a Perkin-Elmer automated model 2400 series II CHNS/O analyzer. TGA/DTG analysis was carried out using a Perkin-Elmer Pyris 6 TGA up to $900^{\circ} \mathrm{C}$ in a closed perforated aluminium pan under inert environment to characterize the manganese complex at a $10^{\circ} \mathrm{C} / \mathrm{min}$ heating rate. A Perkin-Elmer Lambda 1050 UV/vis/NIR spectrometer was used to measure the optical absorption measurements of the manganese oxide nanoparticles. The quartz cuvettes $(1 \mathrm{~cm}$ path length) was used to carry the solution into the instrument employing toluene as a solvent. The emission spectra were collected from a Perkin-Elmer LS 55 spectrofluorimeter to measure the photoluminescence of the nanoparticles. The quartz cuvette ( $1 \mathrm{~cm}$ path length) was also utilized to carry the solution using toluene as a solvent. Powder X-ray diffraction patterns were recorded at an angle of $2 \theta$ for $2^{\circ}$ values over 10 to $90^{\circ}$ using a Bruker AXS D8 diffractometer equipped with nickel filtered $\mathrm{Cu}-\mathrm{K} \alpha$ radiation $(\lambda=1.5418 \AA)$ at $40 \mathrm{kV}, 40 \mathrm{~mA}$, at a normal room temperature. Transmission electron microscopy (TEM) was carried out using a JEOL 1010 TEM, with an accelerating voltage of $100 \mathrm{kV}$, Mega view III camera and Soft Imaging Systems TEM software on a lacey carbon copper grids which was previously prepared by placing 1 or 2 drop of manganese oxide nanoparticles in toluene on the grid.

\section{RESULTS AND DISCUSSION}

The chemical reaction between 2-hydroxy-1-naphthaldehyde, amine and manganese acetate in methanol at $50{ }^{\circ} \mathrm{C}$ produced $\operatorname{bis}(\mathrm{N}$-cyclohexyl-2-hydroxy-1-naphthaldehydato)manganese(II) complex (Scheme-I). The precursor was then used to synthesize TOPO capped manganese oxide nanoparticles by thermal decomposition. The purity of the manganese complex was confirmed by elemental analysis, FTIR spectroscopy, melting point and TGA/DTA.

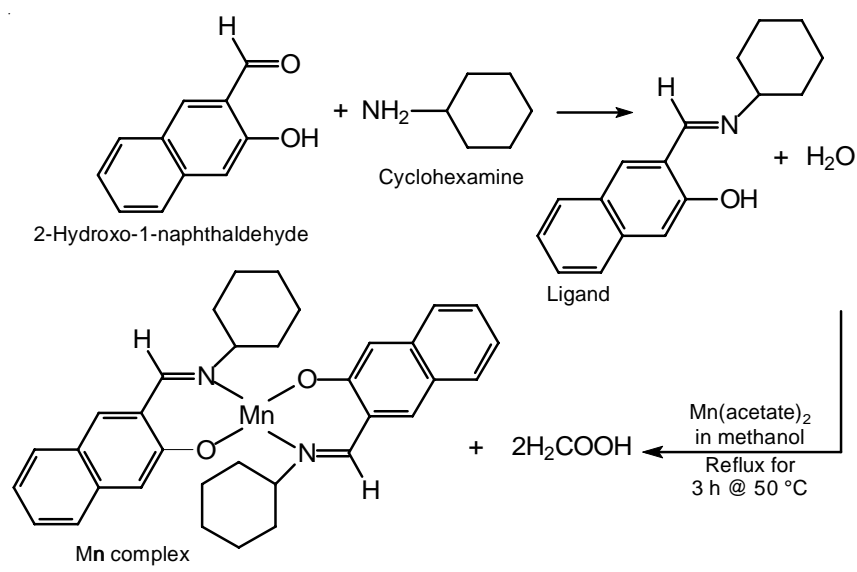

Scheme-I: Preparation of the bis(N-cyclohexyl-2-hydroxy-1-naphthaldehydato)manganese(II) complex

Spectroscopic and thermal studies: The FTIR spectrum of bis( $N$-cyclohexyl-2-hydroxy-1-naphthaldehydato)manganese(II) complex in Fig 1a revealed the characteristic -C-H peaks from the benzene ring located at $2935-2216 \mathrm{~cm}^{-1}$ along with the strong bands at $1634-1537 \mathrm{~cm}^{-1}$ that are ascribed to a stretching vibration of $\mathrm{C}=\mathrm{N}$ groups of imine. The presence of a strong band was observed at $1391 \mathrm{~cm}^{-1}$ which is due to the 

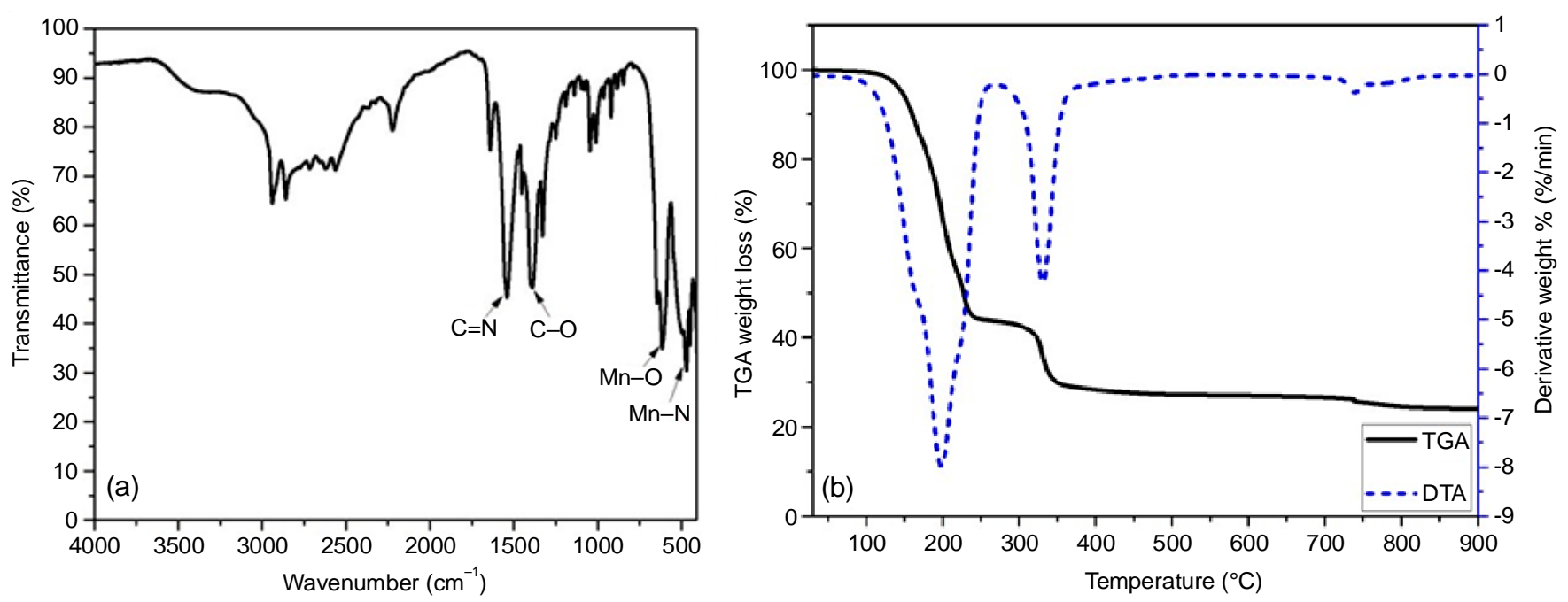

Fig. 1. FTIR spectra and TGA/DTA curves of bis(N-cyclohexyl-2-hydroxy-1-naphthaldehydato)manganese(II) complex

phenolic C-O stretching. The stretching vibrations that confirm the attachment of nitrogen and oxygen to the metal ion were also detected. These stretching bands were located at 615 and $469 \mathrm{~cm}^{-1}$ which are ascribed to $\mathrm{Mn}-\mathrm{O}$ and $\mathrm{Mn}-\mathrm{N}$ bonds, which is also found is similar to reported results [32,37].

Thermal decomposition profile and purity of manganese complex was investigated using the thermogravimetric analysis (TGA). Fig. 1b shows TGA and DTG curves of the manganese complex. The TGA analysis which is supported by the DTG graph on the doted lines displayed two decomposition stages at 134 to $239^{\circ} \mathrm{C}$ and 318 to $347^{\circ} \mathrm{C}$ with the weight losses of 53 and $11 \%$. The first decomposition stage can be ascribed to the loss of ligand moiety with its oxidative degradation to nitrogenmetal-oxide and the second decomposition may be due to the loss of metal nitrogen.

Synthesis of MnO-TOPO capped nanoparticles: Manganese oxide nanoparticles were synthesized from the decomposition bis( $N$-cyclohexyl-2-hydroxy-1-naphthaldehydato)manganese(II) complex in TOPO at 120,160 and $200{ }^{\circ} \mathrm{C}$ to study the effect of temperature. The effect of concentration of the capping molecule and the complex were also investigated. The

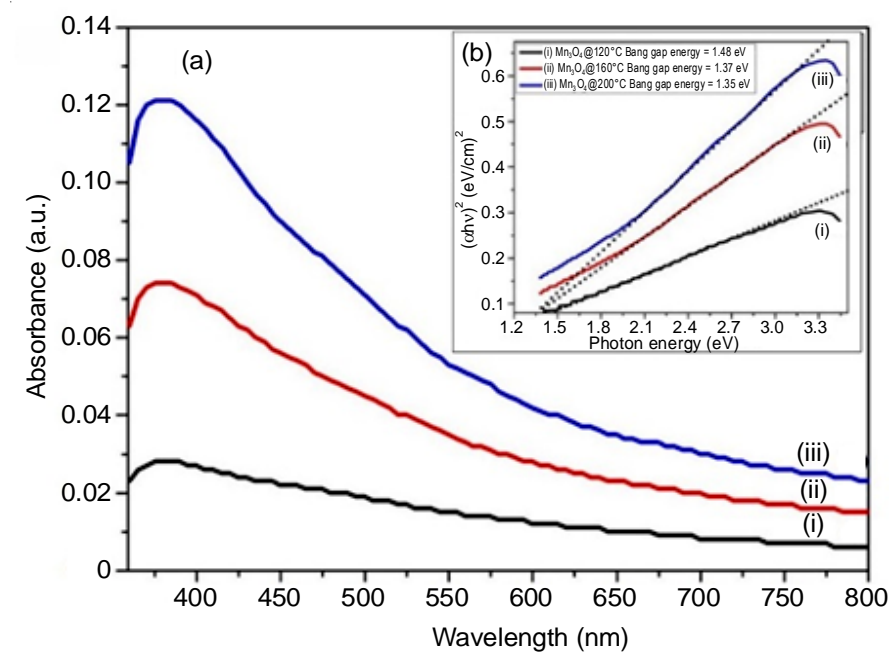

synthesized manganese nanoparticles were analyzed with UVvisible, photoluminescence, XRD and TEM.

Effect of temperature on the formation of $\mathrm{Mn}_{3} \mathrm{O}_{4}$ - $\mathrm{TOPO}$ capped nanoparticles: Fig. 2a shows the UV-visible absorption spectra of $\mathrm{Mn}_{3} \mathrm{O}_{4}$ that were synthesized at 120, 160 and $200{ }^{\circ} \mathrm{C}$ were recorded in the range $250-800 \mathrm{~nm}$. The spectra show flat absorption maximum at 371,377 and $379 \mathrm{~nm}$ which was increased as the temperature was increased. Fig. $2 \mathrm{~b}$ displays the vacancy energy level plots of $(\alpha h v)^{2}$ as a function of hv. The $\mathrm{Mn}_{3} \mathrm{O}_{4}$ nanoparticles synthesized at different temperatures has energy band gab of $1.48,1.37$ and $1.35 \mathrm{eV}$.

Emission spectra of $\mathrm{Mn}_{3} \mathrm{O}_{4}$ nanoparticles with an excitation wavelength $350 \mathrm{~nm}$ at room temperature are shown in Fig. 2c. The spectra of the synthesized nanoparticles shows two strong and wide emission peaks around 408-409 and 433-434 nm. The emission spectrum of $\mathrm{Mn}_{3} \mathrm{O}_{4}$ nanoparticles synthesized at higher temperature exhibit a strong intensed third peak at $456 \mathrm{~nm}$.

The XRD patterns of synthesized nanoparticles are shown in Fig. 3. The pattern of nanoparticles that were prepared at a lower temperature [Fig. 3(i)] revealed a mixture of tetragonal

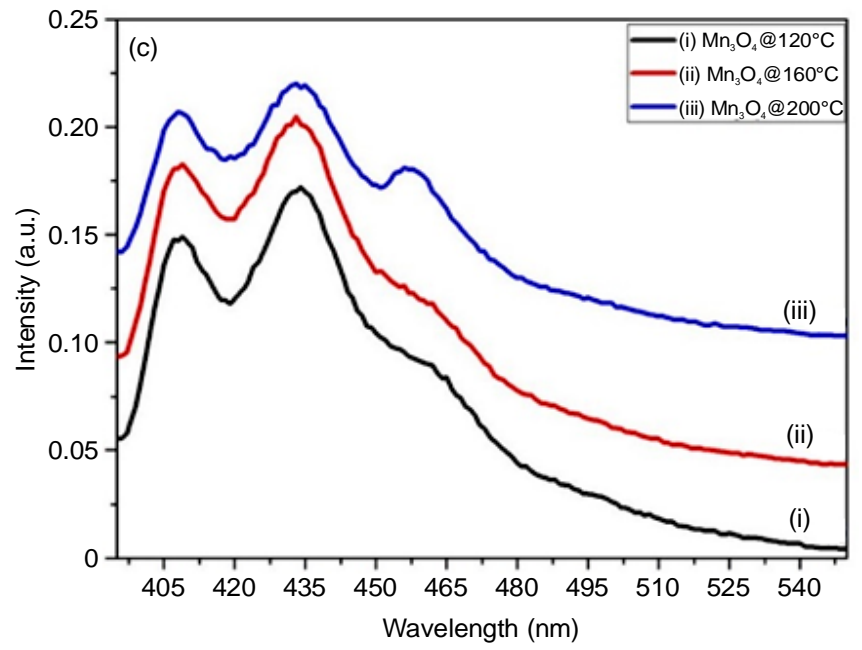

Fig. 2. Absorption (a), tauc plot (b) and emission (c) spectra of $\mathrm{Mn}_{3} \mathrm{O}_{4}$-TOPO capped nanoparticles prepared at (i) $120{ }^{\circ} \mathrm{C}$, (ii) $160{ }^{\circ} \mathrm{C}$ and (iii) $200{ }^{\circ} \mathrm{C}$ 
phase intrinsic hausmannite $\mathrm{Mn}_{3} \mathrm{O}_{4}$ (JCPDS: No. 24-0734), with major thirteen peaks that exactly fit the (101), (112), (200), (103), (211), (004), (220), (204), (105), (312), (303), (321), (224) and (400) together with monoclinic birnessite $\mathrm{MnO}_{2}$ (JCPDS: No. 80-1098) with four peaks that correspond to (001), (002), (111) and (020) miller indices. The manganese oxide nanoparticles that were prepared at higher temperatures of 160 and $200^{\circ} \mathrm{C}$ [Fig. 3(ii) and (iii)] showed a single phase of tetragonal intrinsic hausmannite $\mathrm{Mn}_{3} \mathrm{O}_{4}$ (JCPDS: No. 24-0734) which is an indication of the formation of the well crystallized and highly purified particles. Similar results were reported by Xiao et al. [38].

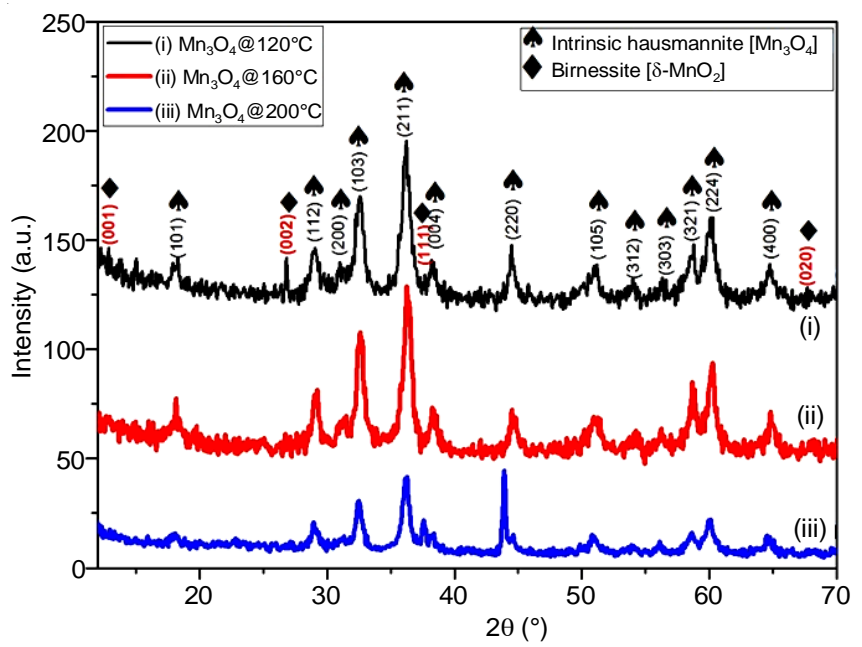

Fig. 3. XRD patterns of $\mathrm{Mn}_{3} \mathrm{O}_{4}$-TOPO capped nanoparticles prepared at (i) $120{ }^{\circ} \mathrm{C}$, (ii) $160{ }^{\circ} \mathrm{C}$ and (iii) $200{ }^{\circ} \mathrm{C}$
TEM analysis of nanoparticles (Fig. 4) were carried out to reveal the particle sizes and micrographs of the particles. All the samples that were prepared at different temperatures showed spherical particles. The average particle sizes for the manganese oxide nanoparticles synthesized at 120, 160 and $200{ }^{\circ} \mathrm{C}$ were found to be $3.52 \pm 0.343,6.03 \pm 0.900$ and 7.11 $\pm 0.755 \mathrm{~nm}$

Effect of concentrations of capping molecule during the synthesis of $\mathrm{Mn}_{3} \mathrm{O}_{4}$-TOPO capped nanoparticles: The absorption spectra of $\mathrm{Mn}_{3} \mathrm{O}_{4}$ nanoparticles synthesized from different amounts of capping agent at a temperature of $160^{\circ} \mathrm{C}$ are shown in Fig. 5a. The absorption bands for the particles prepared at 5 and $10 \mathrm{~g}$ of TOPO while keeping the amount of the complex constant were observed at $360(3.44 \mathrm{eV})$ and 358 $(3.46 \mathrm{eV}) \mathrm{nm}$. The results revealed that when the concentration of stabilizer is increased, the absorption peak becomes red shifted towards the higher wavelength.

The emission spectra of nanoparticles synthesized at different concentration of TOPO are represented in Fig. 5b. The emission peaks were broad which indicate polydispersity of the particles. The emission maxima of manganese oxide nanoparticles were red shifted from their respective absorption bands and observed at 408 and $433 \mathrm{~nm}$ for the particles prepared with $5 \mathrm{~g}$ while the nanoparticles synthesized at $10 \mathrm{~g}$ of TOPO showed the emission peaks at 409 and $434 \mathrm{~nm}$.

The manganese oxide nanoparticles that were prepared at different concentrations of TOPO (Fig. 6a) showed a single phase of tetragonal intrinsic hausmannite $\mathrm{Mn}_{3} \mathrm{O}_{4}$ (JCPDS: No. 24-0734) with peaks at (101), (112), (200), (103), (211), (004), (220), (105), (312), (303), (321), (224) and (400) correspon-
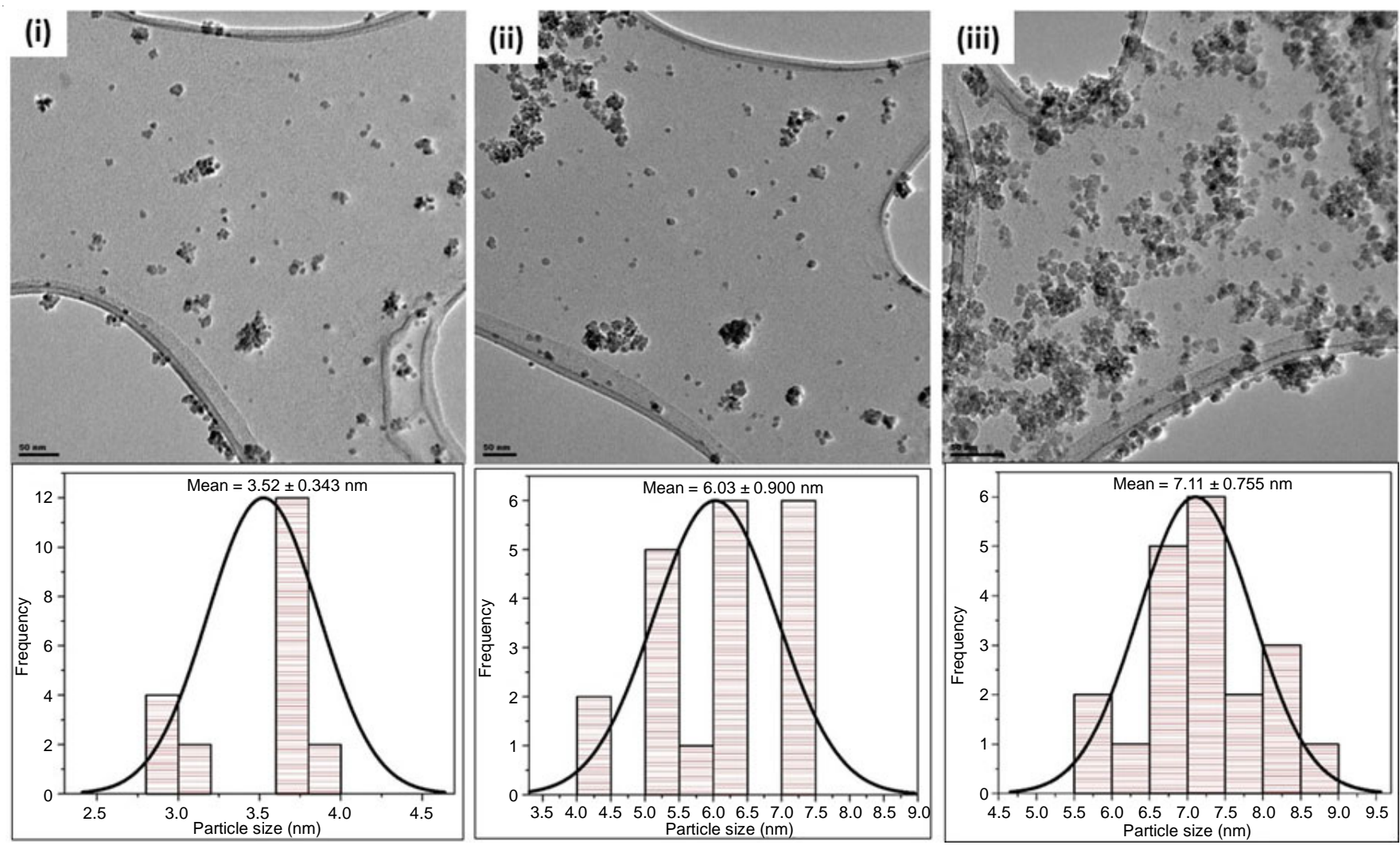

Fig. 4. TEM images of $\mathrm{Mn}_{3} \mathrm{O}_{4}$-TOPO capped nanoparticles prepared at (i) $120^{\circ} \mathrm{C}$, (ii) $160{ }^{\circ} \mathrm{C}$ and (iii) $200{ }^{\circ} \mathrm{C}$ 

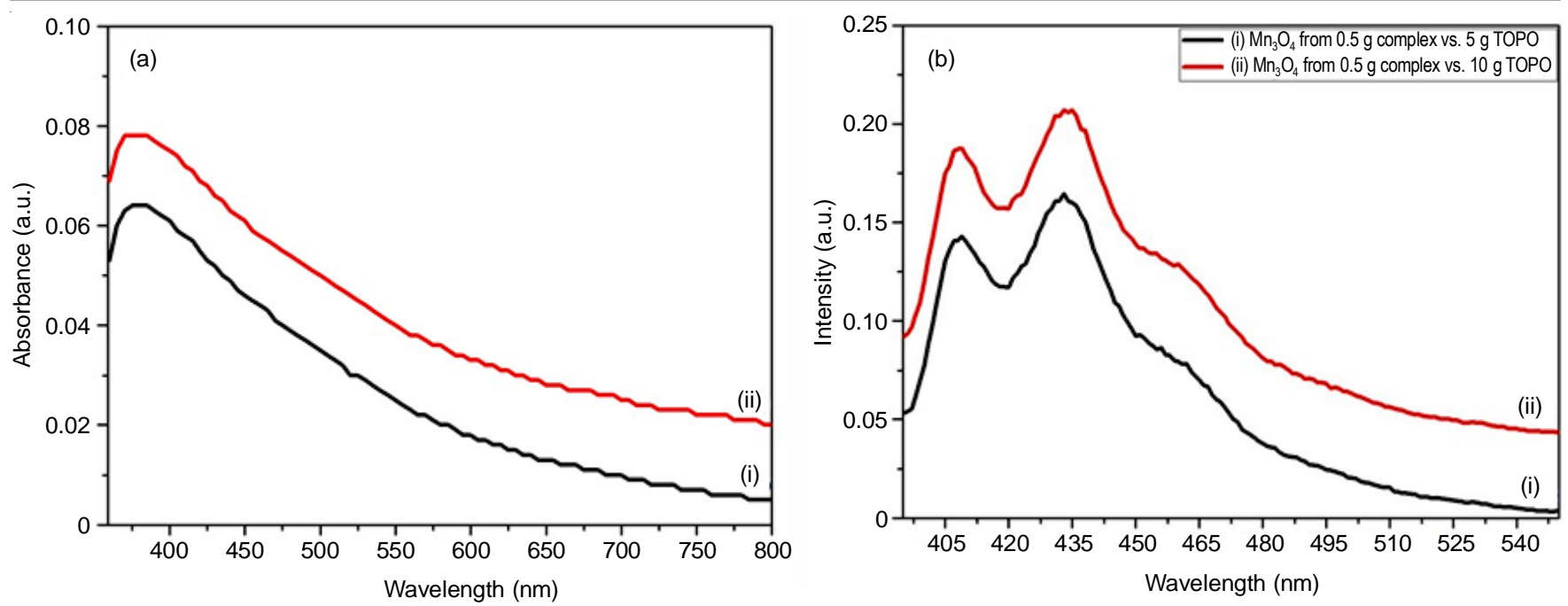

Fig. 5. Absorption (a) and emission (b) spectra (a) of $\mathrm{Mn}_{3} \mathrm{O}_{4}$ nanoparticles capped with (i) $5 \mathrm{~g}$ and (ii) $10 \mathrm{~g}$ of $\mathrm{TOPO}$ at $160{ }^{\circ} \mathrm{C}$

(a)

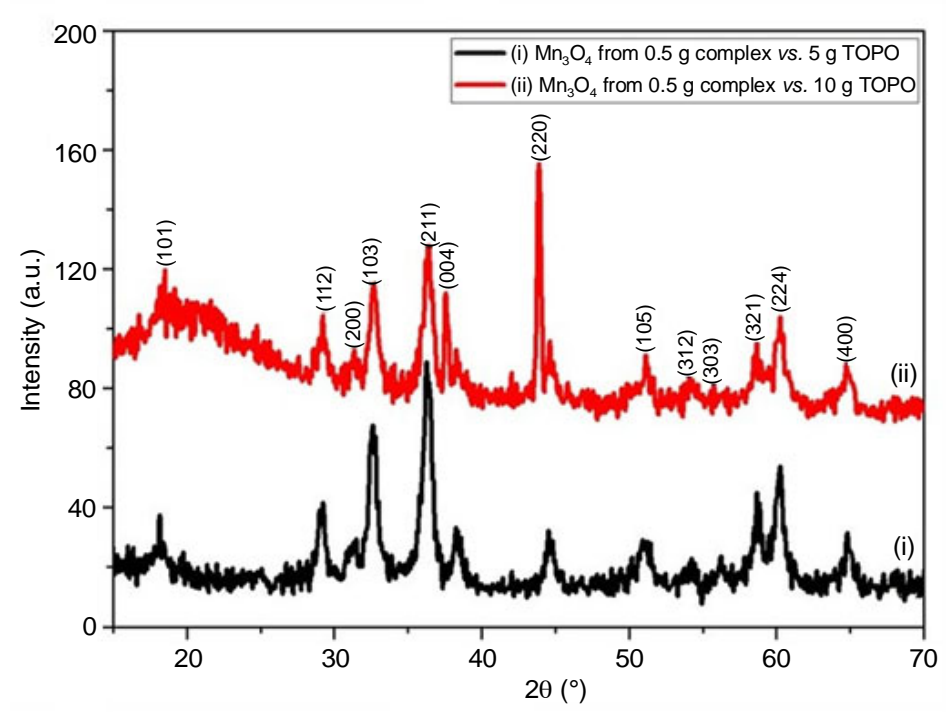

(b)

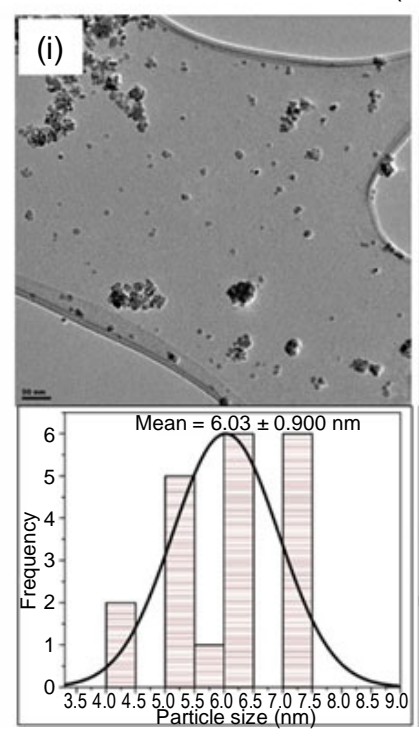

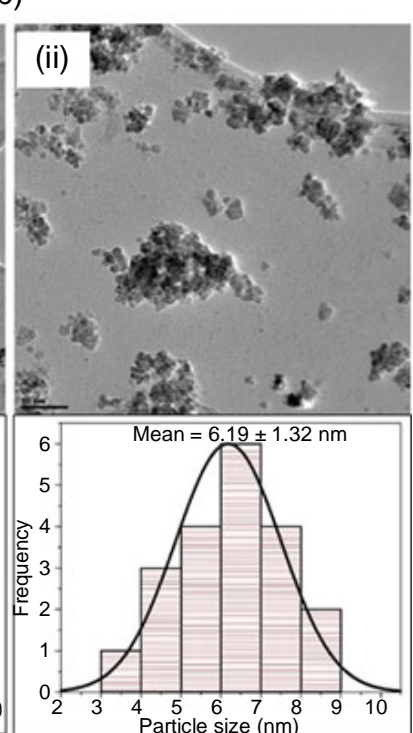

Fig. 6. XRD patterns (a) and TEM images (b) of $\mathrm{Mn}_{3} \mathrm{O}_{4}$ nanoparticles capped with (i) $5 \mathrm{~g}$ and (ii) $10 \mathrm{~g}$ of $\mathrm{TOPO}$ at $160{ }^{\circ} \mathrm{C}$

ding to $18.43^{\circ}, 29.23^{\circ}, 31.42^{\circ}, 32.67^{\circ}, 36.43^{\circ}, 37.68^{\circ}, 43.95^{\circ}$, $51.31^{\circ}, 54.13^{\circ}, 55.38^{\circ}, 58.67^{\circ}, 60.23^{\circ}, 64.78^{\circ}$. The TEM micrograms of synthesized nanoparticles in Fig. $6 \mathrm{~b}$ revealed spherical particles which were increasing as the concentration of TOPO was increased. The average particle sizes were found to be $6.03 \pm 0.900$ and $6.19 \pm 1.321 \mathrm{~nm}$.

Effect of concentrations of the precursor during the synthesis of $\mathrm{Mn}_{3} \mathrm{O}_{4}$-TOPO capped nanoparticles: The effect of the amount of manganese complex was also investigated by decomposing 0.5 or $1 \mathrm{~g}$ of bis( $N$-cyclohexyl-2-hydroxy-1naphthaldehydato)manganese (II) complex into $5 \mathrm{~g}$ of TOPO at $160^{\circ} \mathrm{C}$. The absorption spectra of $\mathrm{Mn}_{3} \mathrm{O}_{4}$ nanoparticles synthesized from different concentrations of the complex are displayed in Fig. 7a. The absorption peaks becomes blue shifted towards the lower wavelength when the amount of precursor was increased. The absorption band were observed at $377 \mathrm{~nm}(3.29 \mathrm{eV})$ and $371 \mathrm{~nm}(3.34 \mathrm{eV})$ for the nanoparticles synthesized with 0.5 and $1 \mathrm{~g}$ of the complex.
The emission spectra of $\mathrm{Mn}_{3} \mathrm{O}_{4}$ nanoparticles that were synthesized from different concentrations of the complex are displayed in Fig. 7b. The emission maxima of $\mathrm{Mn}_{3} \mathrm{O}_{4}$ nanoparticles at an excitation wavelength of $350 \mathrm{~nm}$ were red shifted from their respective absorption bands. The emission peaks were located at 408 and $433 \mathrm{~nm}$ for nanoparticles synthesized with $0.5 \mathrm{~g}$ of complex while the particles prepared with $1 \mathrm{~g}$ of precursor showed their emission maxima at 407 and $432 \mathrm{~nm}$.

Fig. 8a shows XRD diffraction pattern of manganese oxide nanoparticles that were prepared at different concentrations of the complex. All the patterns showed the peaks that were indexed to tetragonal intrinsic hausmannite $\mathrm{Mn}_{3} \mathrm{O}_{4}$ (JCPDS: No. 24-0734) at (101), (112), (200), (103), (211), (004), (220), (105), (312), (303), (321), (224) and (400) miller indices. The peaks were very wide, which is an indication of the presence of smaller particles. The TEM images of synthesized $\mathrm{Mn}_{3} \mathrm{O}_{4}$ nanoparticles in Fig. 8b displayed spherical particles which were decreasing as the concentration of the precursor was 

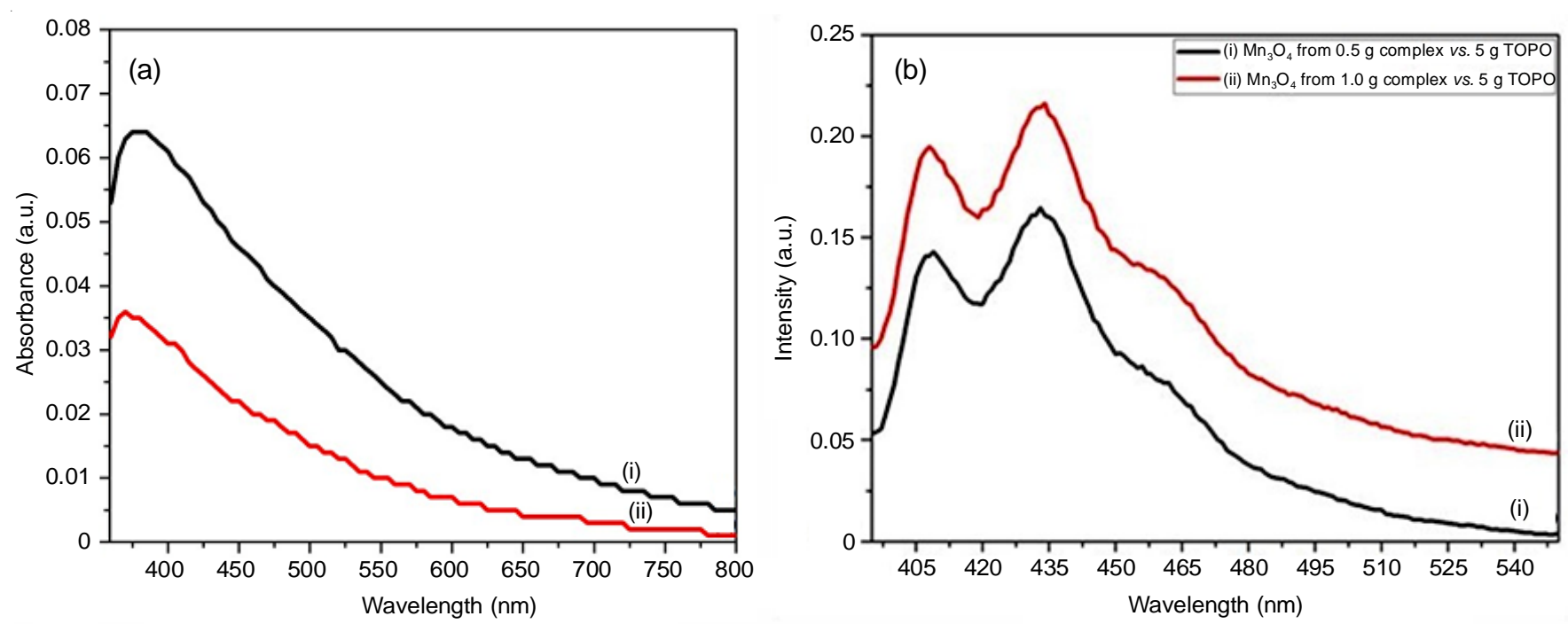

Fig. 7. Absorption (a) and emission (b) spectra of $\mathrm{Mn}_{3} \mathrm{O}_{4}$-TOPO capped nanoparticles prepared with (i) $0.5 \mathrm{~g}$ and (ii) $1 \mathrm{~g}$ of the precursor at $160{ }^{\circ} \mathrm{C}$

(a)

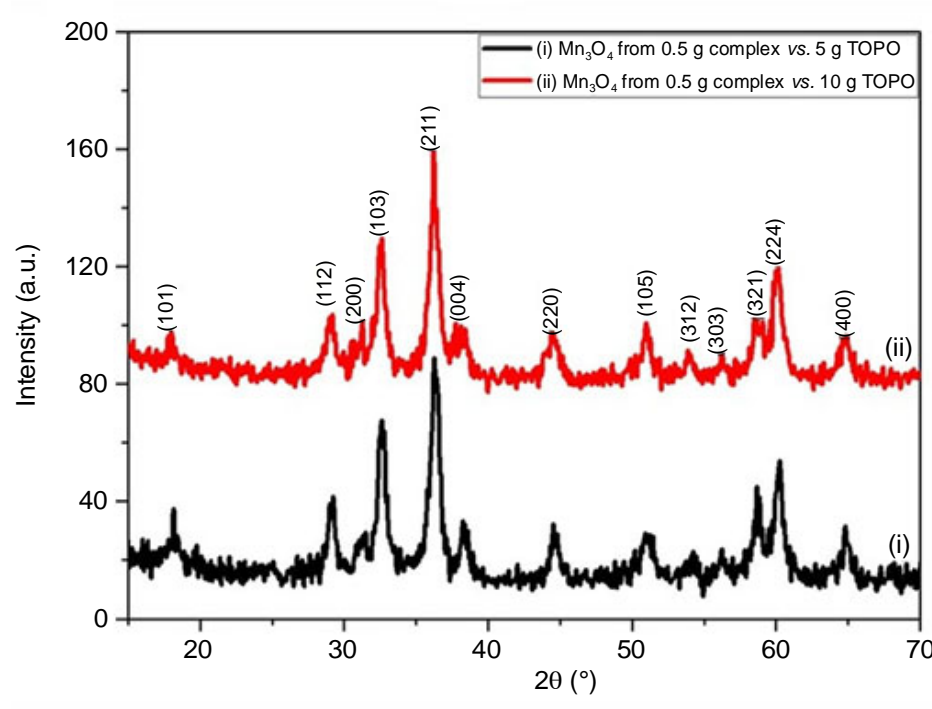

(b)

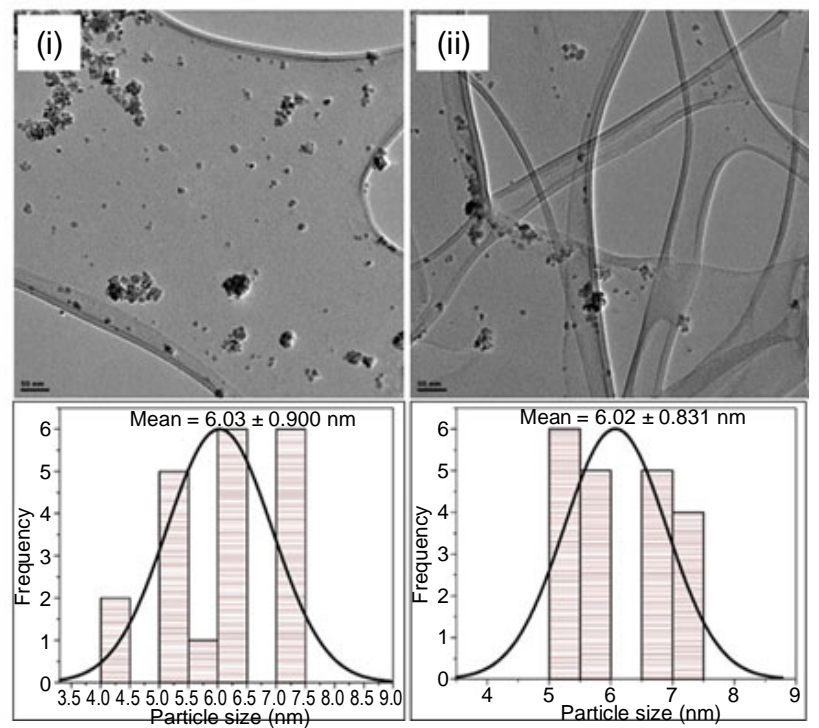

Fig. 8. XRD patterns (a) and TEM images (b) of $\mathrm{Mn}_{3} \mathrm{O}_{4}-\mathrm{TOPO}$ capped nanoparticles prepared with $0.5 \mathrm{~g}$ (i) and $1 \mathrm{~g}$ (ii) of the precursor at $160{ }^{\circ} \mathrm{C}$

increased. The average particle sizes were found to be $6.03 \pm$ 0.900 and $6.02 \pm 0.831 \mathrm{~nm}$.

\section{Conclusion}

The preparation of bis( $N$-cyclohexyl-2-hydroxy-1-naphthaldehydato)manganese(II) complex and the synthesis of monodisperse $\mathrm{Mn}_{3} \mathrm{O}_{4}$ nanoparticles through thermal decomposition method has been accomplished. The optical properties of the synthesized particles showed that the temperature of the synthesis, concentration of stabilizer and precursor has a special role on the preparation of $\mathrm{Mn}_{3} \mathrm{O}_{4}$ nanoparticles. X-ray diffraction patterns of the nanoparticles synthesized at higher temperatures displayed tetragonal intrinsic hausmannite $\mathrm{Mn}_{3} \mathrm{O}_{4}$ phase. TEM of all the synthesized nanoparticles at different temperatures showed spherical shaped particles that were increased in sizes at the higher concentration of capping molecule and decreased in sizes, when the amount of precursor was increased.

\section{ACKNOWLEDGEMENTS}

The author acknowledges The National Research Foundation South Africa (NRF) and Vaal University of Technology for funding this project.

\section{CONFLICT OF INTEREST}

The authors declare that there is no conflict of interests regarding the publication of this article.

\section{REFERENCES}

1. V. Arun, N. Sridevi, P.P. Robinson, S. Manju and K.K.M. Yusuff, $J$. Mol. Catal. Chem., 304, 191 (2009);

https://doi.org/10.1016/j.molcata.2009.02.011.

2. K.C. Gupta and A.K. Sutar, Coord. Chem. Rev., 252, 1420 (2008); https://doi.org/10.1016/j.ccr.2007.09.005.

3. Y.-B. Dong, H.-Q. Zhang, J.-P. Ma, R.-Q. Huang and C.-Y. Su, Cryst. Growth Des., 5, 1857 (2005); https://doi.org/10.1021/cg0501534. 
4. A.K. Ghosh, D. Ghoshal, J. Ribas, G. Mostafa and N.R. Chaudhuri, Cryst. Growth Des., 6, 36 (2006); https://doi.org/10.1021/cg050423i.

5. P. Phuengphai, S. Youngme, P. Kongsaeree, C. Pakawatchai, N. Chaichit, S.J. Teat, P. Gamez and J. Reedijk, CrystEngComm, 11, 1723 (2009); https://doi.org/10.1039/b901607d.

6. P.A. Vigato and S. Tamburini, Coord. Chem. Rev., 248, 1717 (2004); https://doi.org/10.1016/j.cct.2003.09.003.

7. D. Pucci, A. Bellusci, A. Crispini, M. Ghedini and M. La Deda, Inorg. Chim. Acta, 357, 495 (2004); https://doi.org/10.1016/j.ica.2003.08.015.

8. C. Biswas, M.G.B. Drew, A. Figuerola, S. Gómez-Coca, E. Ruiz, V. Tangoulis and A. Ghosh, Inorg. Chim. Acta, 363, 846 (2010); https://doi.org/10.1016/j.ica.2009.12.048.

9. K. Fan, C. Cao, Y. Pan, D. Lu, D. Yang, J. Feng, L. Song, M. Liang and X. Yan, Nat. Nanotechnol., 7, 459 (2012); https://doi.org/10.1038/nnano.2012.90.

10. C.R. Olsen, T.J. Smith, J.S. Embley, J.H. Maxfield, K.R. Hansen, J.R. Peterson, A.M. Henrichsen, S.D. Erickson, D.C. Buck, J.S. Colton and R.K. Watt, Nanotechnology, 28, 195601 (2017); https://doi.org/10.1088/1361-6528/aa68ae.

11. H.-Y. Su, Y. Gorlin, I.C. Man, F. Calle-Vallejo, J.K. Nørskov, T.F. Jaramillo and J. Rossmeisl, J. Phys. Chem. Chem. Phys., 14, 14010 (2012); https://doi.org/10.1039/c2cp40841d.

12. A. Ramírez, D. Friedrich, M. Kunst and S. Fiechter, Chem. Phys. Lett., 568-569, 157 (2013); https://doi.org/10.1016/j.cplett.2013.03.054.

13. M.M. Najafpour, F. Rahimi, M. Amini, S. Nayeri and M. Bagherzadeh, Dalton Trans., 41, 11026 (2012); https://doi.org/10.1039/c2dt30553d.

14. S.L. Brock, N. Duan, Z.R. Tian, O. Giraldo, H. Zhou and S.L. Suib, Chem. Mater, 10, 2619 (1998); https://doi.org/10.1021/cm980227h.

15. S.L. Suib, J. Mater. Chem., 18, 1623 (2008); https://doi.org/10.1039/b714966m.

16. X. Fang, X. Lu, X. Guo, Y. Mao, Y.S. Hu, J. Wang, Z. Wang, F. Wu, H. Liu and L. Chen, Electrochem. Commun., 12, 1520 (2010); https://doi.org/10.1016/i.elecom.2010.08.023.

17. W.S. Seo, H.H. Jo, K. Lee, B. Kim, S.J. Oh and J.T. Park, Angew. Chem. Int. Ed., 43, 1115 (2004); https://doi.org/10.1002/anie.200352400.

18. S.T. Myung, S. Komaba and N. Kumagai, Electrochim. Acta, 47, 3287 (2002); https://doi.org/10.1016/S0013-4686(02)00248-7.

19. Y. Lvov, B. Munge, O. Giraldo, I. Ichinose, S.L. Suib and J.F. Rusling, Langmuir, 16, 8850 (2000); https://doi.org/10.1021/la000110j

20. X.-L. Luo, J.-J. Xu, W. Zhao and H.-Y. Chen, Biosens. Bioelectron., 19, 1295 (2004); https://doi.org/10.1016/j.bios.2003.11.019.
21. X. Liu, C. Chen, Y. Zhao and B. Jia, J. Nanomater, Article ID 736375 (2013); https://doi.org/10.1155/2013/736375.

22. R. Ramprasath, G. Kalpana and T. Pandiselvi, Impl. J. Interdiscipl. Res., 2, 1409 (2016).

23. M.M. Najafpour, F. Rahimi, E.-M. Aro, C.-H. Lee and S.I. Allakhverdiev, J. R. Soc. Interface, 9, 2383 (2012); https://doi.org/10.1098/rsif.2012.0412.

24. Y.Q. Chang, X.Y. Xu, X.H. Luo, C.P. Chen and D.P. Yu, J. Cryst. Growth, 264, 232 (2004); https://doi.org/10.1016/j.jcrysgro.2003.11.117.

25. S.K. Park, A. Jin, S.H. Yu, J. Ha, B. Jang, S. Bong, S. Woo, Y.E. Sung and Y. Piao, Electrochim. Acta, 120, 452 (2014); https://doi.org/10.1016/j.electacta.2013.12.018.

26. H. Chang, Y. Guo, L. Yang, Q. Liu, W. Feng, J. Liang and G. Rao, J. Solid State Chem., 177, 4341 (2004);

https://doi.org/10.1016/j.jssc.2004.07.040.

27. E. Finocchio and G. Busca, Catal. Today, 70, 213 (2001); https://doi.org/10.1016/S0920-5861(01)00419-9.

28. S.K. Apte, S.D. Naik, R.S. Sonawane, B.B. Kale, N. Pavaskar, A.B. Mandale and B.K. Das, Mater. Res. Bull., 41, 647 (2006); https://doi.org/10.1016/j.materresbull.2005.08.028.

29. Z.W. Chen, J.K.L. Lai and C.H. Shek, Scr. Mater, 55, 735 (2006); https://doi.org/10.1016/j.scriptamat.2006.05.041.

30. M. Salavati-Niasari, F. Davar and M. Mazaheri, Poly, 27, 3467 (2008); https://doi.org/10.1016/j.poly.2008.04.015.

31. X. Tai, X. Yin, Q. Chen and M. Tan, Molecules, 8, 439 (2003); https://doi.org/10.3390/80500439.

32. T. Ozkaya, A. Baykal, H. Kavas, Y. Ko"seogфllu and M.S. Toprak, Physica B, 403, 3760 (2008); https://doi.org/10.1016/j.physb.2008.07.002.

33. L. He, G. Zhang, Y. Dong, Z. Zhang, S. Xue and X. Jiang, Nano-Micro Lett., 6, 38 (2014); https://doi.org/10.1007/BF03353767.

34. M. Wang, G.-H. Lee, Y. Wang, T.-Y. Dong and H.-H. Wei, J. Chin. Chem. Soc., 49, 825 (2002); https://doi.org/10.1002/jccs.200200118.

35. R. Vafazadeh, V. Hayeri and A.C. Willis, Polyhedron, 29, 1810 (2010); https://doi.org/10.1016/j.poly.2010.02.030.

36. T. Akitsu and Y. Einaga, Polyhedron, 25, 1089 (2006); https://doi.org/10.1016/j.poly.2005.07.048.

37. M. Sebastian, V. Arun, P.P. Robinson, A.A. Varghese, R. Abraham, E. Suresh and K.K.M. Yusuff, Polyhedron, 29, 3014 (2010); https://doi.org/10.1016/i.poly.2010.08.016.

38. W. Xiao, J.S. Chen and X.W.D. Lou, CrystEngComm, 13, 5685 (2011); https://doi.org/10.1039/c1ce05711a. 